\title{
Health needs of older populations affected by humanitarian crises in low- and middle- income countries: a systematic review
}

\author{
Emma Massey, James Smith and Bayard Roberts ${ }^{*}$ (1)
}

\begin{abstract}
Background: The combination of global demographic changes and a growing number of humanitarian crises in middle-income countries that have a higher life expectancy has led to an increase in the number of older populations affected by humanitarian crises. The aim of this review was to systematically examine evidence on the health needs of older populations in humanitarian crises, including both armed conflicts and natural disasters, in low- and middleincome countries (LMICS).

Methods: A systematic review methodology was used. The search strategy used terms related to older populations and humanitarian crises in LMICs. Five bibliographic databases were used, along with relevant grey literature sources. Descriptive analysis was used, and a quality assessment conducted using the Newcastle-Ottawa Scale and CASP instruments.

Results: A total of 36 studies were eligible for review. The majority of the studies were cross-sectional, three were cohort studies, and four used qualitative methodologies. The main health outcomes were mental health, physical health, functioning, and nutrition. Vulnerability factors included older age, female gender, being widowed, increased exposure to traumatic events, prior mental health problems, low income and education, and rural residency. Ten studies addressed the responsiveness of health systems and access to such services. The quality of the included studies was generally low.
\end{abstract}

Conclusions: There is an urgent need to strengthen the evidence base on the health needs of older populations in humanitarian crises.

Keywords: Violence, Disasters, Ageing, Health

\section{Background}

The proportion of older people is growing faster than any other age group globally. Approximately $12 \%$ of the world's population is aged 60 and over and the number of older people is estimated to surpass 1 billion by 2020 . By 2050, there will be nearly as many people aged 60 and over as children aged under 15 [1]. Currently, twothirds of the world's older people live in low- and middle-income countries, which is where humanitarian crises are more likely to occur and where the humanitarian impact is greater.

\footnotetext{
* Correspondence: bayard.roberts@lshtm.ac.uk London School of Hygiene and Tropical Medicine, 15-17 Tavistock Place, London, WC1H 9SH, UK
}

An estimated 172 million people (all ages) are currently affected by armed conflict worldwide, [2] including over 59 million people forcefully displaced from their homes as either internally displaced persons (IDPs) or as refugees. Natural disasters are also estimated to affect 175 million people annually [3]. The combination of global demographic changes and a growing number of humanitarian crises in middle-income countries with higher life expectancy led to an increase in the number of older populaOlder populations are more likely to be disproportionately affected by humanitarian crises [7]. Older age is associated with increased likelihood of disability and ill health which can limit functioning and physical mobility, 
and impede access to health services. Ageing also increases dependency on others for financial and social support. These collective vulnerabilities put older populations at a higher risk during humanitarian crises when health risks are increased and support networks and existing social infrastructure compromised [8]. Specific health risks for older populations in humanitarian crises include: greater susceptibility to ill health, malnutrition, disability and injury; difficulties in accessing health services (including psychological services); inappropriate health services such as services not addressing noncommunicable diseases which older people are more likely to suffer from; failure to collect data on health needs of older people; and broader social and economic marginalisation $[9,10]$.

While older populations are recognised as a vulnerable group in humanitarian crises, $[11,12]$ the particular needs of older populations in humanitarian crises appear poorly understood [13]. Reviews have been conducted on crisis-affected older populations, [14-16] but these have not been systematic, have focused on natural disasters only, and on high-income countries where the health needs and health sector resources and responses are likely very different compared to low- and middleincome countries (LMICs) where the vast majority of crisis-affected populations live.

The aim of this review was to systematically examine evidence on the health needs of older populations in humanitarian crises in LMICs. The specific objectives were to: identify the vulnerabilities of older populations in humanitarian crises; assess health service access and responsiveness for older populations in humanitarian crises; and evaluate the quality of the evidence.

\section{Methods}

\section{Eligibility criteria}

The population of interest were older populations affected by humanitarian crises in LMICs (with LMICs classified according to Word Bank listings [17]). No age limit was set as the definition of 'older' varies across country contexts. The study population included refugees, returnees, IDPs, and non-displaced crisis-affected people. Humanitarian crises were defined as a serious disruption of the functioning of a community or a society causing widespread human, material, economic or environmental losses which exceed the ability of the affected community or society to cope using its own resources, necessitating a request to national or international level for external assistance [18]. Humanitarian crises included both armed conflict and natural disasters [19]. Natural disaster events included earthquakes, tsunamis, floods, hurricanes, landslides, and volcanic eruptions (see Additional file 1 for the full list of events). All health outcomes were included. Research on military or veteran military populations was excluded, as were studies of an older population that had experienced a crisis at a younger age. Studies of all-age populations showing age as a risk factor but not focusing specifically on older populations were excluded.

Primary published and grey literature using quantitative and qualitative methods were included. All languages were included. No date restrictions were set (the end date was 18 July 2016).

\section{Search strategy}

The following bibliographic databases were used: Medline, Embase, Global Health, Psychinfo, and IBSS. The search methodology consisted of three strings, with terms related to LMICs, humanitarian crises, and older populations. Free-text searching was used, and subject heading $(\mathrm{MeSH})$ were also used for Medline. The search terms are listed in Additional file 1. Broad search terms such as 'elderly' and 'humanitarian' were applied to the Desastres database (mixed published and grey literature) and also to the following grey literature sources: UNHCR, MSF Field Research, HelpAge International, Handicap International, International Committee of the Red Cross (ICRC), WHO Institutional Repository for Information Sharing (IRIS), Open Grey, ReliefWeb, PsycEXTRA, ALNAP, and Google (first ten pages only).

\section{Study selection and data extraction}

Study selection involved a four stage process: removal of duplicates (stage 1); screening by title (stage 2a) and abstract (stage $2 \mathrm{~b}$ ) and then full text (stage 2c); grey literature screening and review of the reference lists of the final selected studies (stage 3); and final review and analysis of the selected studies (stage 4).

The information extracted from the final selected studies included: author/date, location, crisis/population type, older age definition, methods, health outcomes/ measurement, and findings that related to the three study objectives. Where both bivariate and multivariate analyses were performed, only multivariate results were extracted. In relation to objective one, where statistical significance tests were used, only results that were considered statistically significant $(p<0.05)$ were extracted. The study screening, data extraction, and quality assessment was conducted separately by EM and JS and any differences discussed and reconciled.

\section{Analysis and quality assessment}

Descriptive analysis was used given the heterogeneous nature of study context, population exposure, health outcomes, and study methodologies. Findings were organised by the three study objectives, and then into commonly recurring themes. For quality appraisal, quantitative studies were appraised using the Newcastle- 
Ottawa Scale (NOS), [20]. with cohort studies given a score of 1-9, and cross-sectional studies given a score of 1-10 (using a modified NOS version for cross-sectional studies) [21]. For qualitative studies, the Critical Appraisal Skills Program (CASP) checklist was used, [22]. with studies given a score of 1-10. Higher scores in the quality appraisals indicate better quality. The quality appraisal process sought to identify common strengths/weaknesses, rather than to exclude studies. This review follows the PRISMA Statement for reporting systematic reviews (see Additional file 2 for the completed PRISMA checklist) [23]

\section{Results}

\section{Study selection and characteristics}

Thirty-six studies met the eligibility criteria, [24-59] of which two were from the grey literature [37, 40] (Fig. 1). The most common reasons for exclusion at stage two were studies not reporting: primary research, populations in LMICs, specifically on older populations.

All 36 studies were published between 1989 and 2016, with $64 \%$ published since 2010. Two were qualitative, $[25,34]$ two used mixed methodologies, [40, 47] three were cohort studies, [50,51,55]. and the remaining 29 were cross-sectional. [24, 26-33, 35-39, 41-46, 48, 49, 52-54, 56-59]. Twenty-one studies reported on populations affected by natural disasters, [25-29, 31-34, 36, 39, $41,42,44,48,53,54,56-59] 14$ by armed conflict, [24, $30,35,37,38,40,43,45-47,49-52]$, and one for both crisis types [55]. The definition of older age ranged from $\geq 45$ to $\geq 65$ years of age, with most studies defining it as aged $\geq 60$ years. The majority of studies were conducted in Asia (China, [29, 33, 39, 42, 54, 56-59], India, [28, 53] Sri Lanka, [34, 44] Pakistan $[31,32]$, and Thailand [48]), followed by the Middle East (Lebanon [30, 37, 50-52] and Iran [25-27]), subSaharan Africa (the Democratic Republic of Congo, [24, 43] Ethiopia, [35] Tanzania, [45-47] and Mozambique [49]), Europe (Croatia, [38] Armenia, [36] Georgia [40]), and Latin America (Honduras [41]), and one study covered 21 countries [55].

\section{Vulnerability factors}

\section{Mental health outcomes}

Twenty studies reported mental health and psychosocial outcomes [25, 26, 29-31, 33, 36-42, 44, 48, 52, 53, 56, $58,59]$. A synthesis of key factors associated with mental health outcomes is presented in Table 1, with detailed results given in Table 2 , and a description given below.

Demographic and socio-economic factors Twelve studies observed associations between older age and post-traumatic stress disorder (PTSD), [33, 36, 39, 44, 53], depression, [38, 48, 52]. worse psychological quality of life, [26, 56, 59] psychological distress, [37, 39] symptoms suggestive of psychosomatic disorders, [38] and adjustment disorder [53]. However, one study in the Andaman and Nicobar Islands, India, following the 2004 tsunami, reported that older age was a protective factor against major depressive episodes [53].

Five studies observed that female gender was associated with PTSD, [33] depression, [40, 48] worse psychological quality of life, $[26,56,59]$ and anxiety $[40,58]$. Low education was associated with PTSD [33] and psychological distress [29], but was protective against depression among refugees in Lebanon [52]. Low income was associated with PTSD, [33] depression, [30, 48] and quality of life, [59]. while loss of livelihood was associated with PTSD, [58] all among earthquake survivors in China.

Being widowed, unmarried, single or separated were associated with PTSD, [33] depression, [48] and worse psychological quality of life $[26,56,59]$. Reduced social support was associated with PTSD, [33] depressive symptoms, [42] quality of life, [59] (all in China) and anxiety (refugees in Lebanon), [52] as was a reduced sense of community with depressive symptoms (China) [42]. Regular religious attendance was associated with reduced probability of depression among refugees in Lebanon [30].

One study following the 2003 Bam earthquake in Iran observed that rural residents scored a higher psychological quality of life than affected urban residents [26]. However, rural residents were more likely than urban residents to report sleeplessness and a feeling of depression or helplessness after the 2005 Kashmir earthquake in Pakistan [31].

Exposure to crises, traumatic events and forced displacement Five studies observed greater intensity of exposure to crises increased the risk of PTSD, [36, 41, 58] depression, [42, 58] anxiety, [58] worse psychological quality of life, [26] and psychological distress [41]. Three studies showed an association between bodily injury from a crisis exposure (most commonly in the context of a natural disaster) with PTSD, [33] anxiety [58] and worse psychological quality of life [26]. Three studies with earthquake and Tsunami survivors in Sri Lanka, Thailand, and China reported the effects of loss, disability or injury of a family member on PTSD, [44]. depression, [48] psychological distress, [29] and quality of life [59].

Three studies assessed PTSD levels at 1 year, [58] 15 months, [39] and 3 years [33] after the Wenchuan earthquake in China, and observed PTSD remained high many months and years after the earthquake. The study in Lebanon of long-term Palestinian refugees and shorter-term Syrian refugees found that Palestinian refugees had higher levels of depression and experiencing fear than Syrian refugees (the time period of 


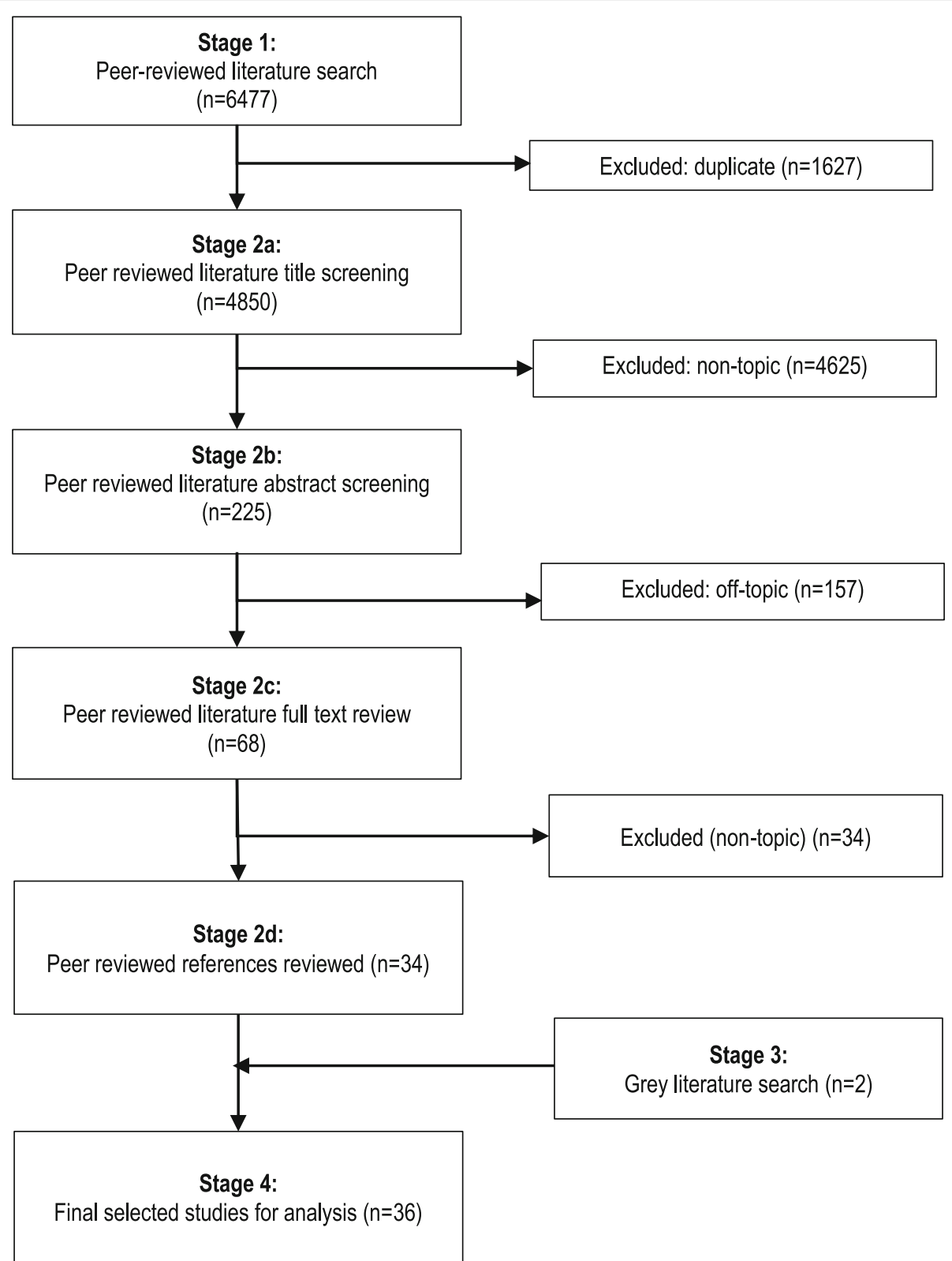

Fig. 1 Results of screening process

displacement was not recorded in the study but we have assumed that Palestinian refugees had been displaced for a longer time than Syrian refugees given their histories of forced displacement) [52]. A qualitative study in Iran found that older populations experienced a significant amount of emotional distress years after the Bam Earthquake, and they found it difficult to move on from the earlier crisis events [25]. Conversely, a study in Georgia found that IDPs displaced for a shorter period of time were more susceptible to depression [40].

Forced displacement and dissatisfaction with current living conditions after a crisis was related to worse psychological quality of life [26] and psychological distress [29] among earthquake survivors in Iran and China respectively, $[26,29]$ and anxiety disorder among Tsunami survivors in India [53]. However, the 2004 Andaman and Nicobar study reported that remaining in the crisis-affected area increased the likelihood of suffering from adjustment disorder [53].

Health problems and illness Five studies found that current or prior health conditions including chronic conditions, 'prior nerves', physical mobility constraints and limited functioning increased the likelihood of 
Massey et al. Conflict and Health (2017) 11:29

Page 5 of 21

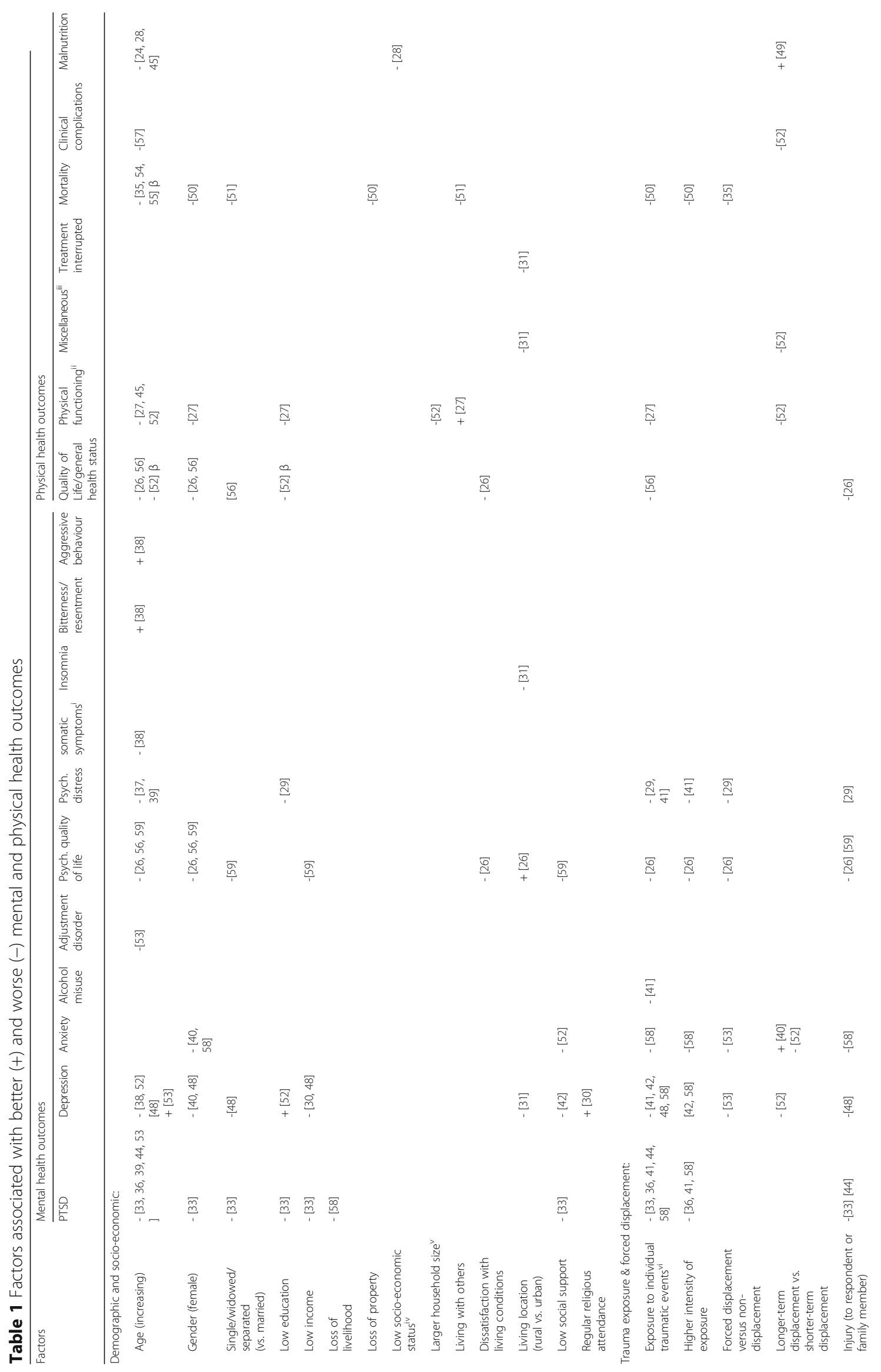




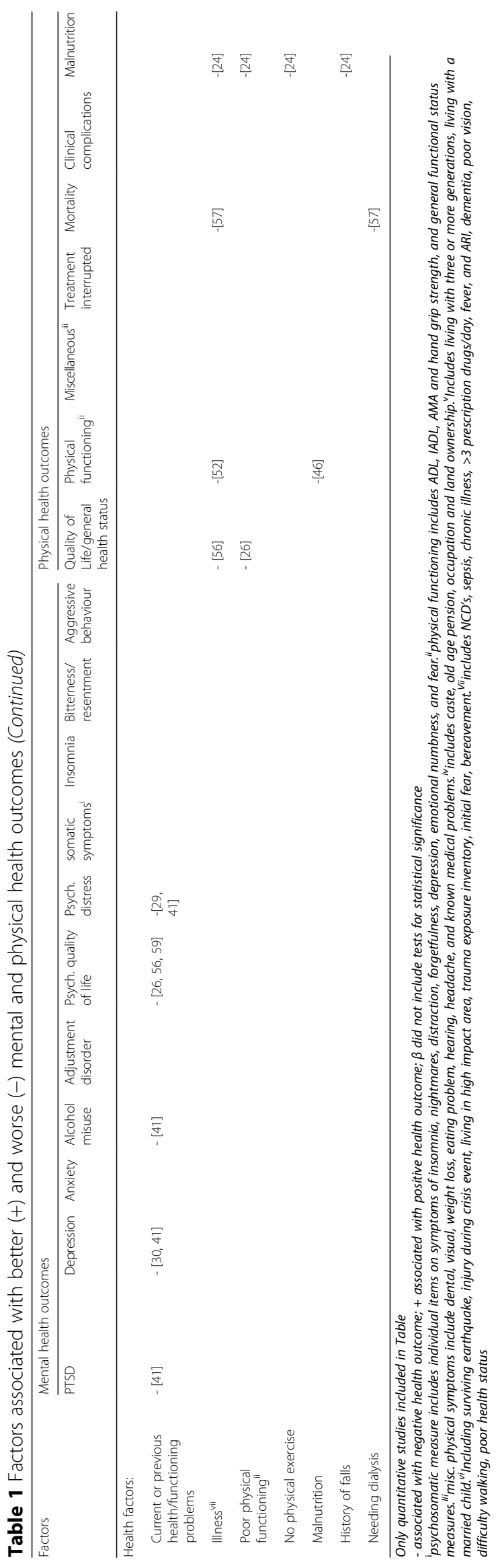




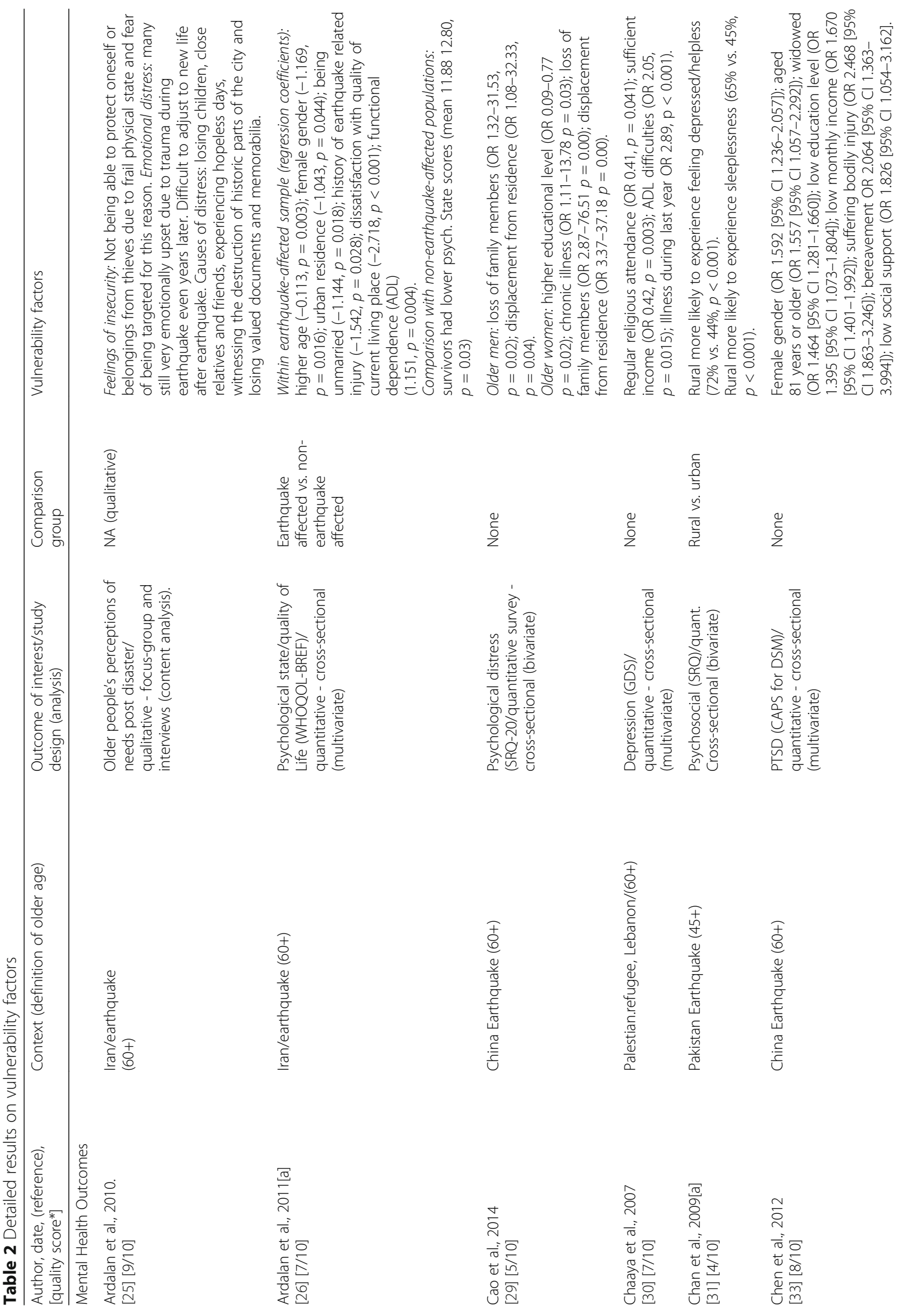


Massey et al. Conflict and Health (2017) 11:29

Page 8 of 21

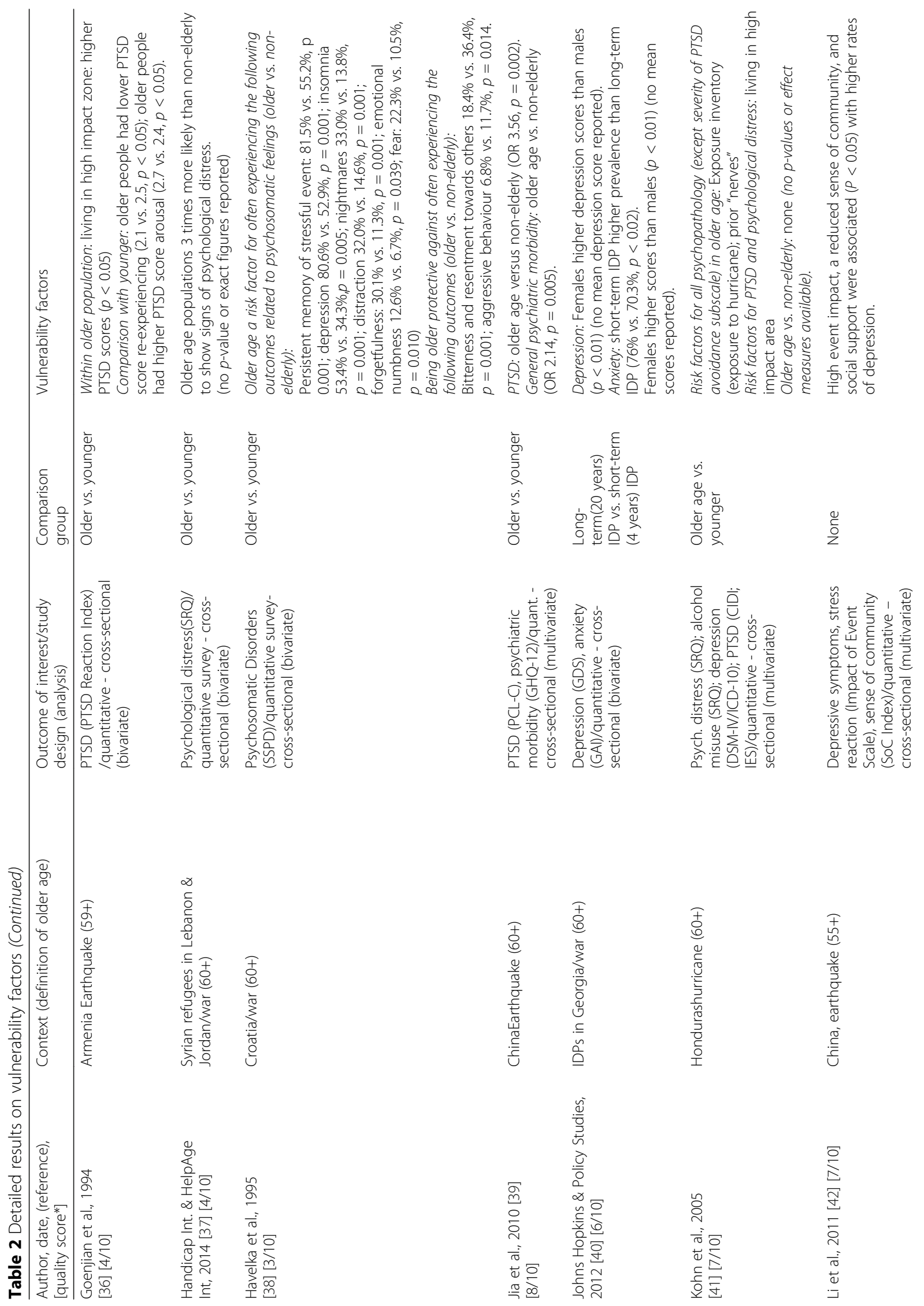




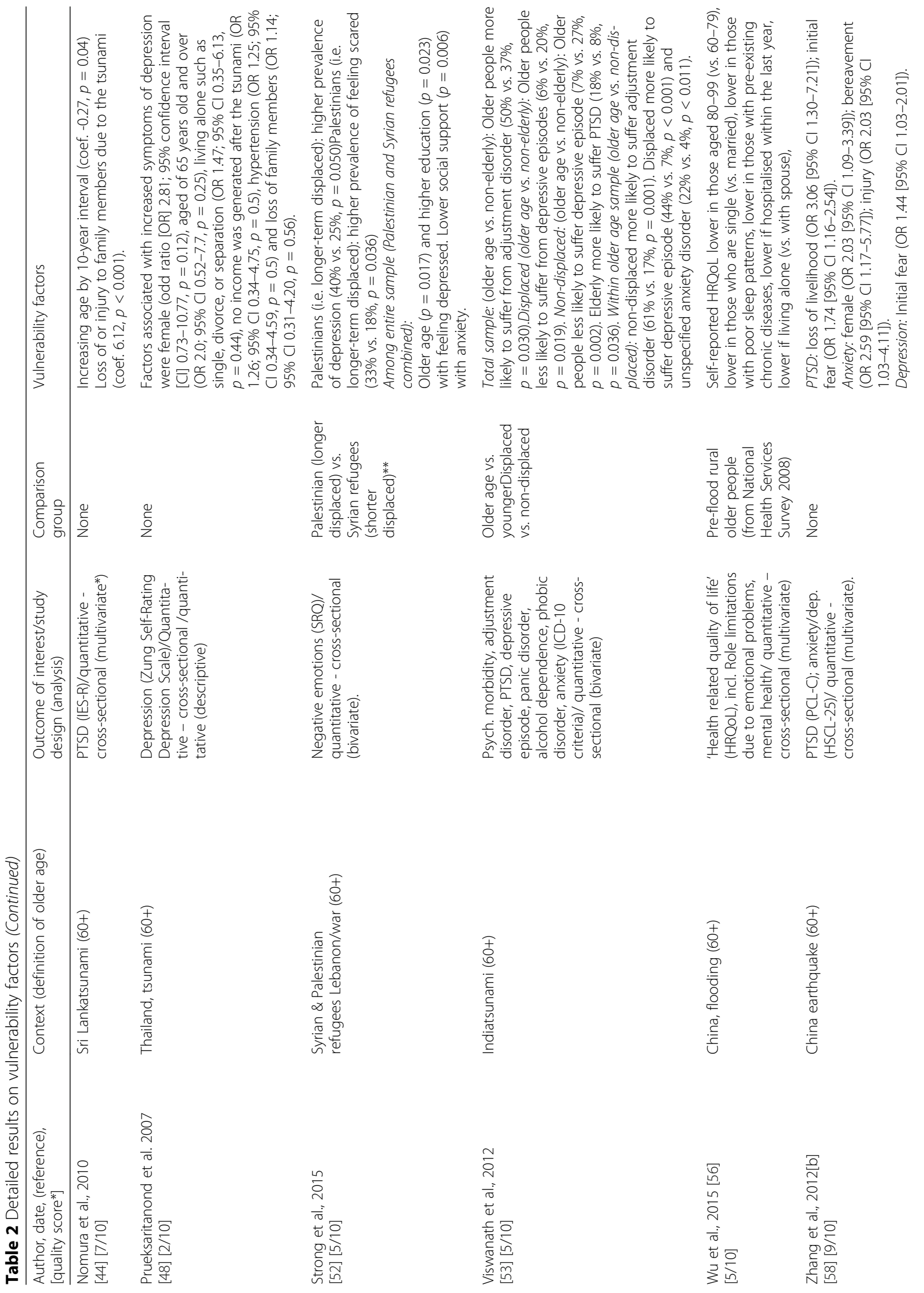




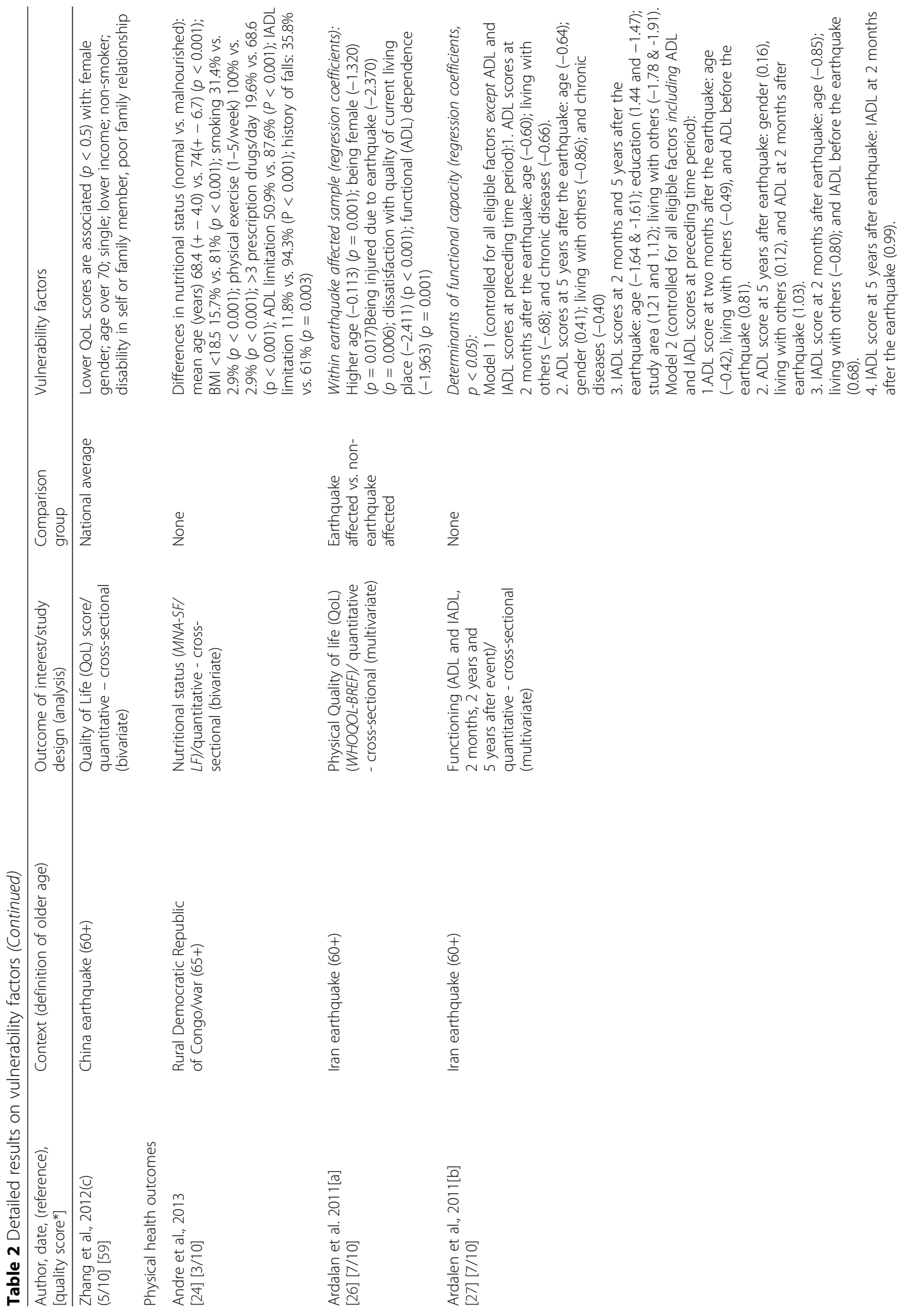


Massey et al. Conflict and Health (2017) 11:29

Page 11 of 21

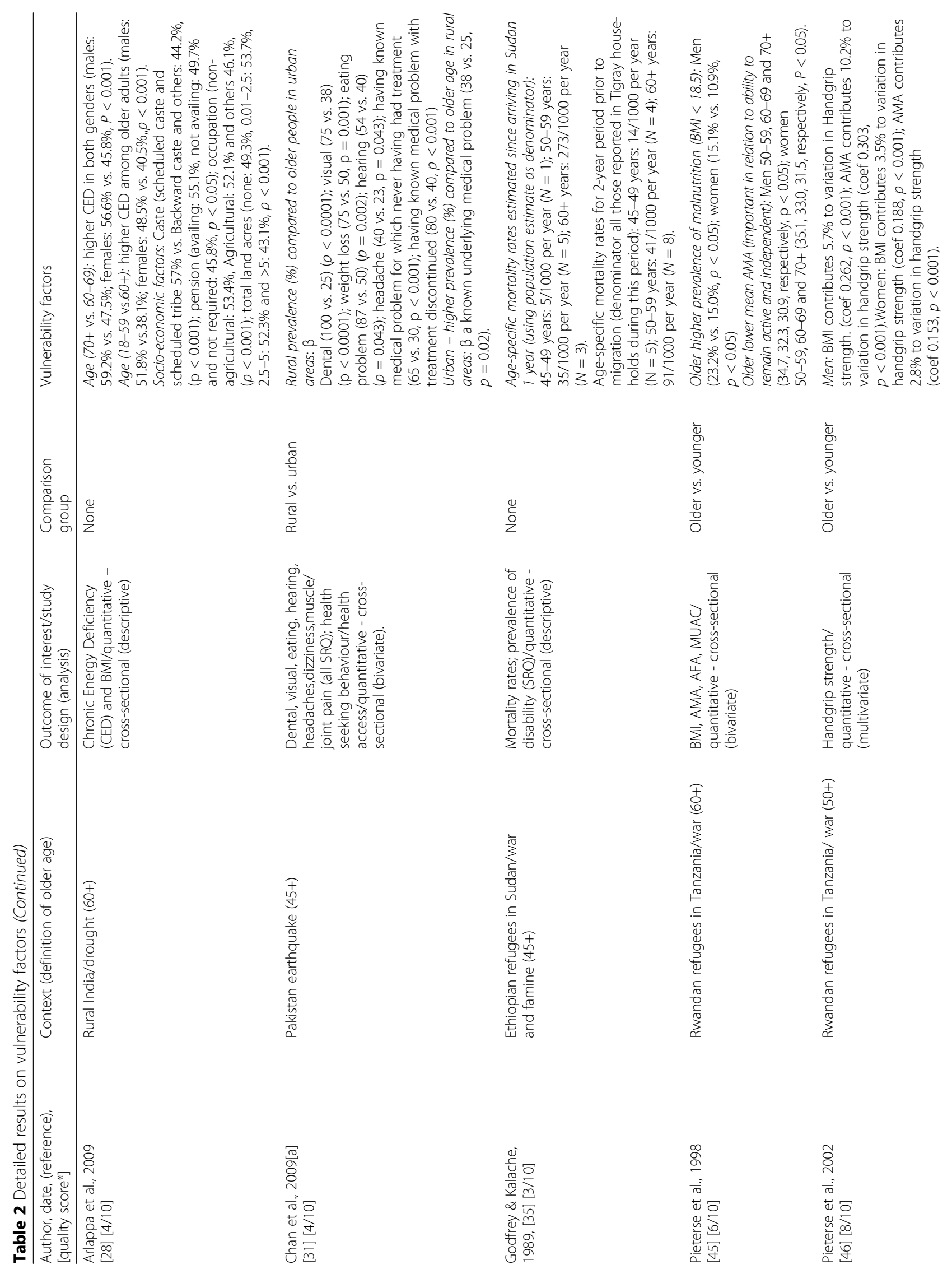




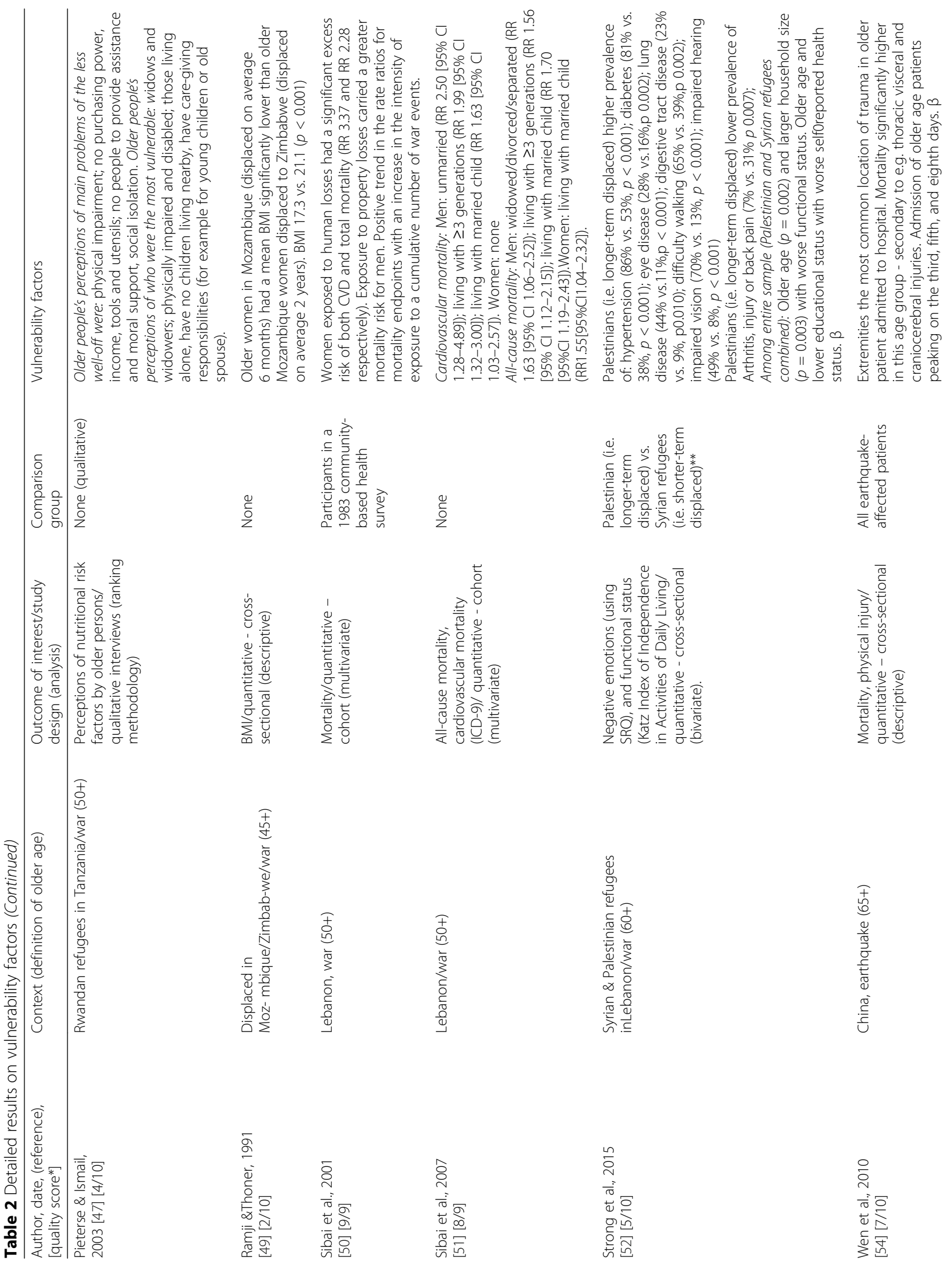




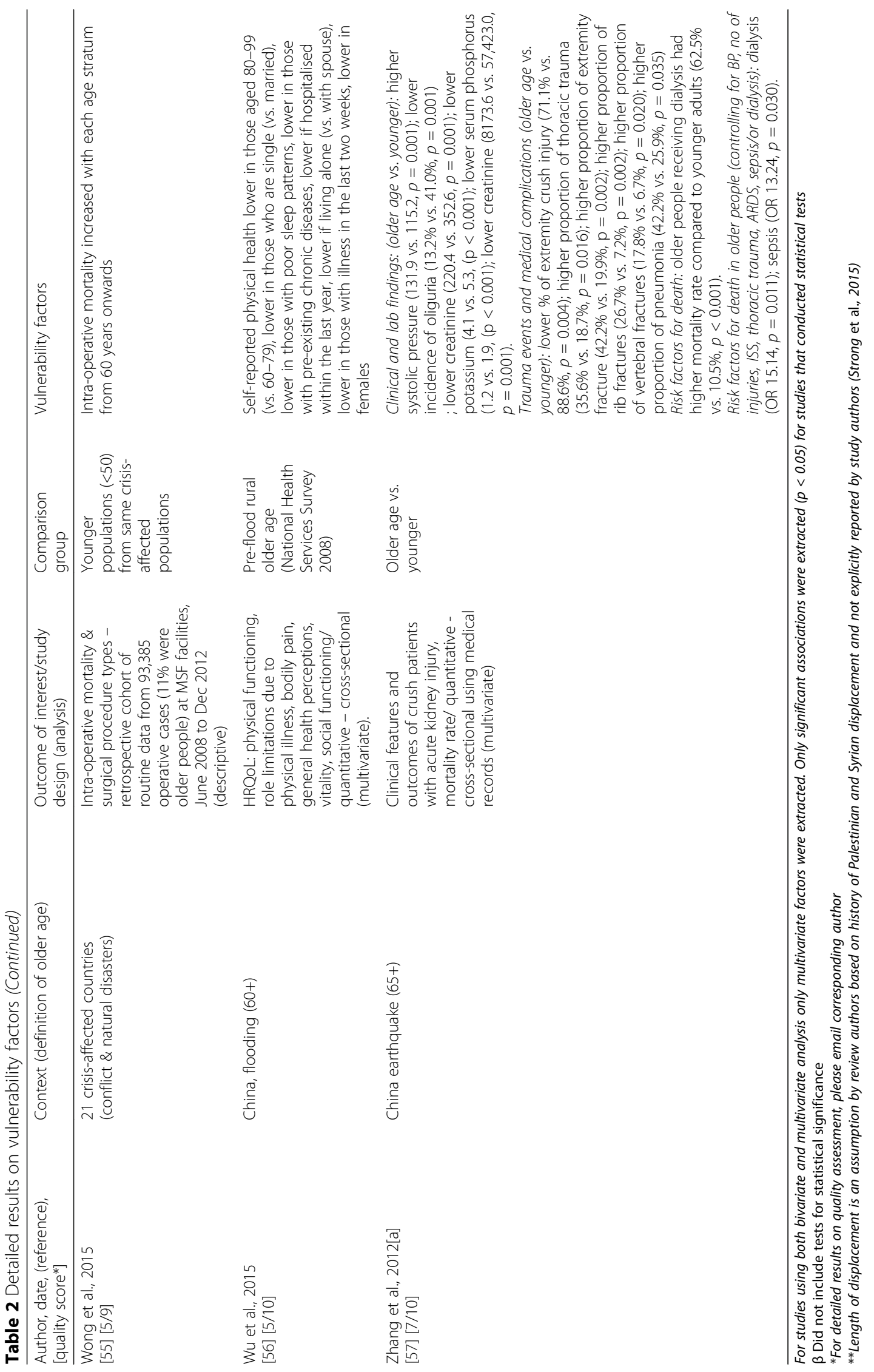



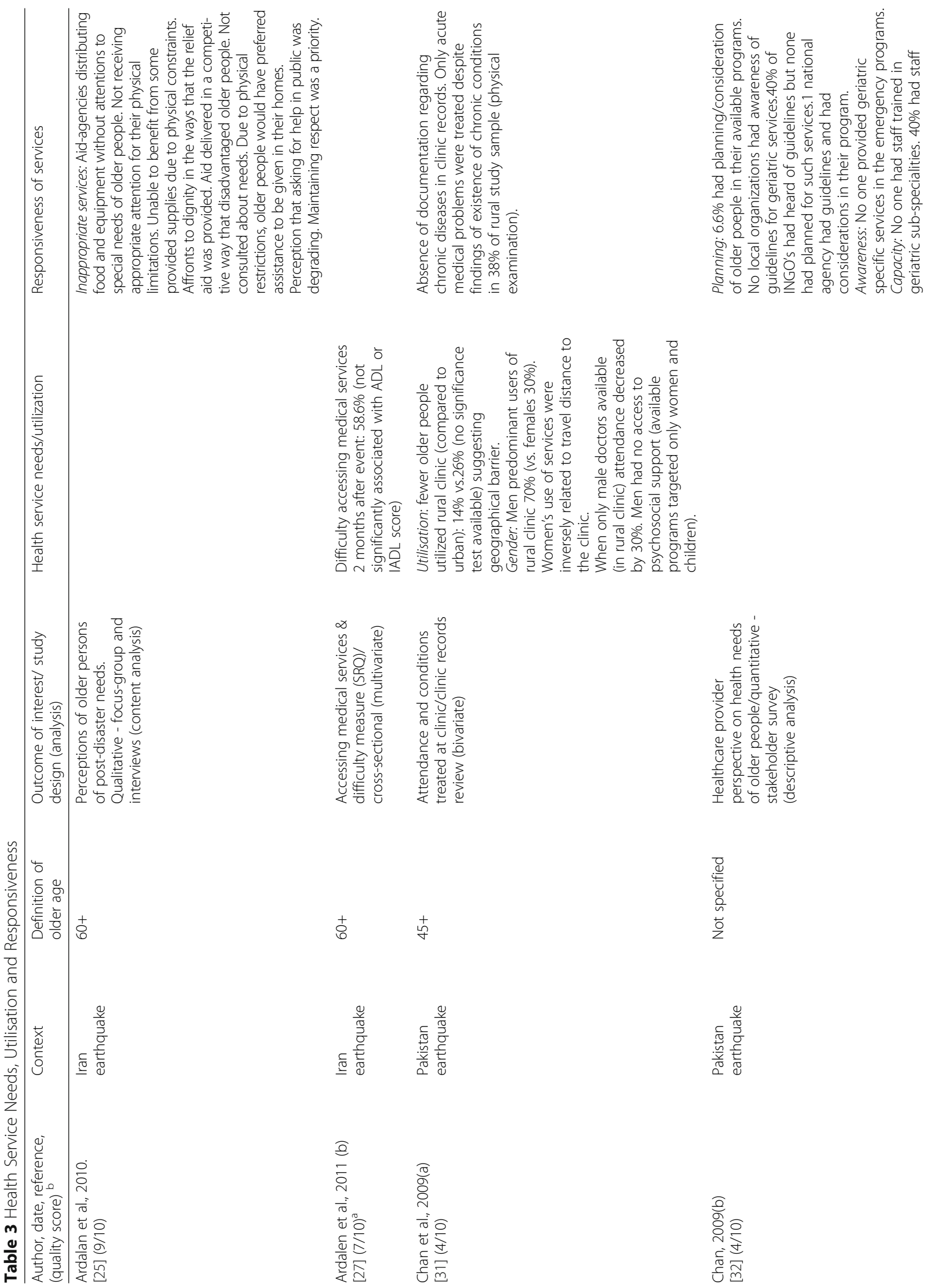

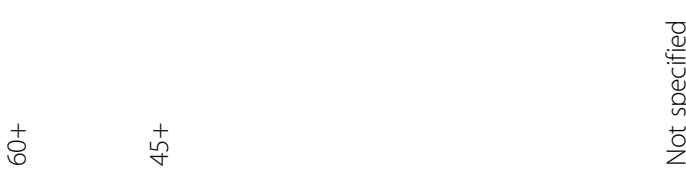

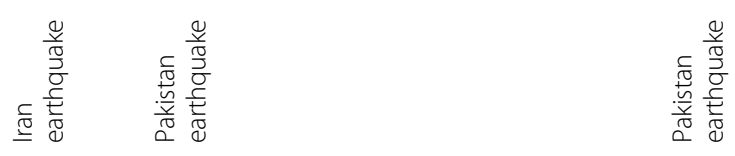

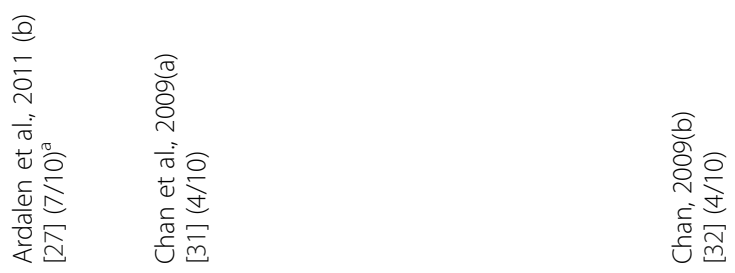




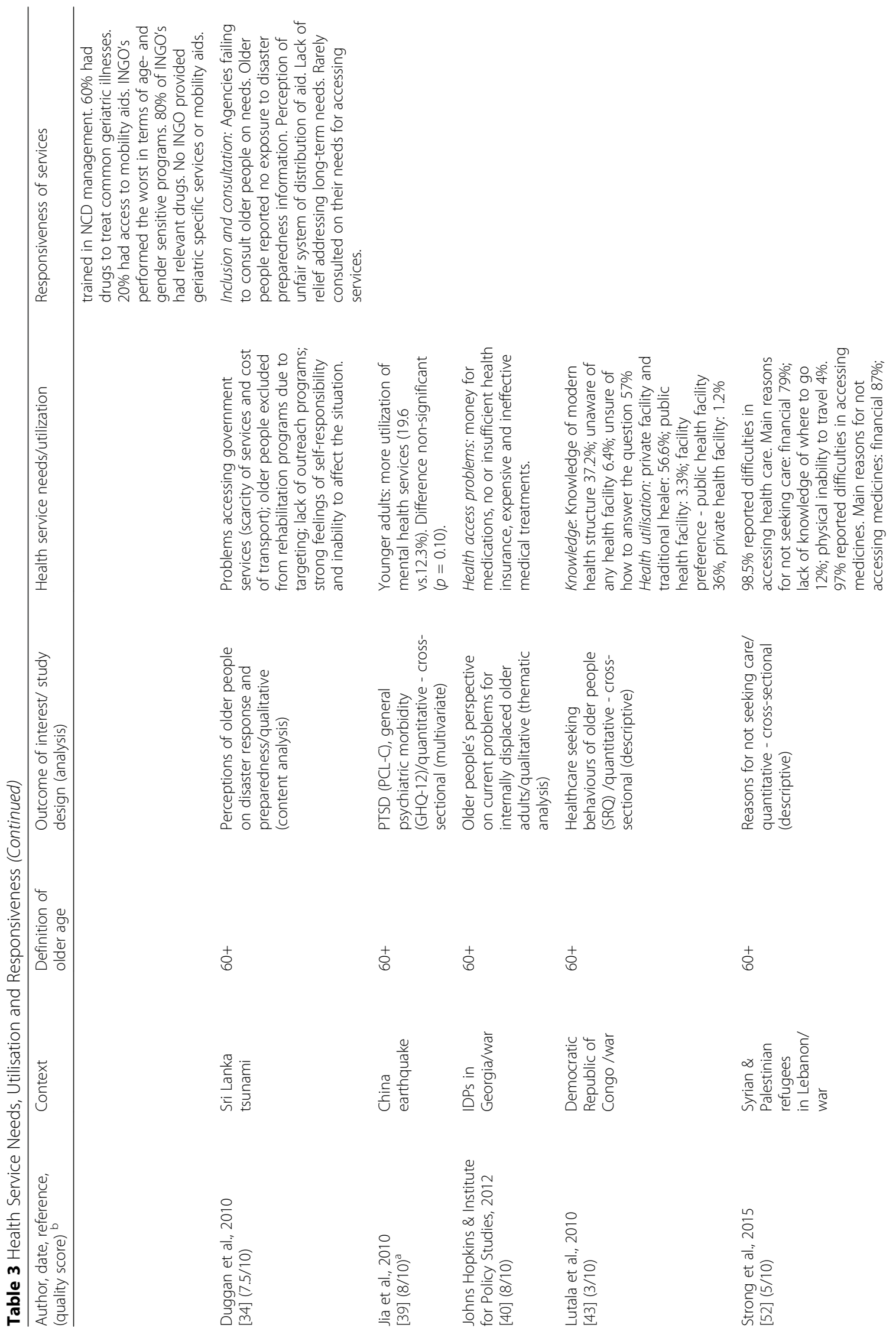




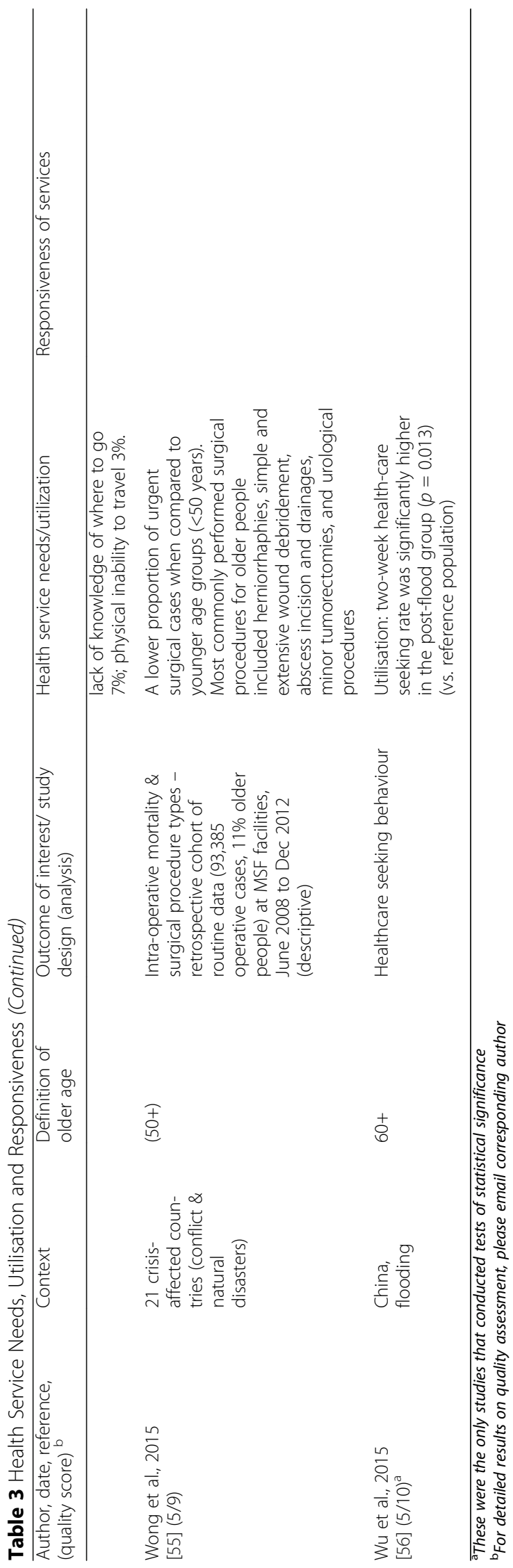


PTSD, [41] depression, [30, 41] alcohol disorder, [41] poor psychological quality of life, $[26,56,59]$ and psychological distress [29].

\section{Physical health, functioning and nutritional outcomes}

Ten studies reported on various physical health outcomes in older populations, $[26,27,31,35,50,51,54-57]$ and six studies reported on nutritional outcomes [24, 28, 45-47, 49] (although three of these were from the same larger study [45-47]). These results are synthesised in Table 1 , with details given in Table 2, and described below.

Demographic and socio-economic factors Older age was associated with lower physical quality of life among earthquake and flood survivors in Iran and China, $[26,56]$ lower physical functioning in Iran, Rwanda, and Syrian refugees in Lebanon, [27, 45, 52] higher mortality risk among Ethiopian refugees in Sudan and earthquake survivors in China, $[35,54]$ worse nutritional outcomes, [24, 28, 45] worse clinical outcomes (except for oliguria) among patients with traumatic injuries following the 2008 Sichuan Earthquake in China, [57] and higher intra-operative mortality in 21 countries [55].

Female gender was associated with lower physical quality of life [26] and physical functioning among earthquake survivors in Iran, [27] and with cardiovascular and all-cause mortality among war-affected persons in Lebanon [50] Low education was associated with worse physical functioning among earthquake survivors in Iran [27] and self-reported health status among refugees in Lebanon [52]. Lower socio-economic status was associated with a higher prevalence of chronic energy deficiency following a period of severe drought in India [28]. The loss of property had a greater mortality risk for war-affected men in Lebanon [50].

Being single, divorced, widowed or separated increased the risk of death from cardiovascular disease and all-cause mortality in Lebanon [51] and worse self-reported health among flood survivors in China [56]. A qualitative study with Rwandan refugees in Tanzania found that older populations perceived that those who lived alone and had no family or spouse to care for them were at the greatest risk of poor nutrition, citing reduced income and inadequate support networks [47]. Conversely, living with others was associated with a worse physical functioning score in the older Bam earthquake survivors in Iran [27]. The study of Palestinian refugees in Lebanon observed living in a larger household size was associated with worse functional status [52].

A study of survivors of the 2005 Kashmir earthquake in Pakistan observed a higher prevalence in rural areas than urban areas of dental, visual, eating, and hearing problems, headache, dizziness, muscle and joint pains, and of established yet untreated medical problems [31].

Trauma exposure and forced displacement The study from Lebanon observed excess risk of both cardiovascular and total mortality following human loss (deaths of close relatives/friends, injuries, kidnappings, and serious threats) among women, and of cumulative exposure to war events among men and women [50]. Flood-affected populations in China reported lower health related quality of life compared to non-flood affected populations [56]. The study of Ethiopian refugees in Sudan observed mortality rates markedly increased one year after migration compared to the pre-migration period [35]. The study of displaced Palestinian and Syrian refugees in Lebanon observed longer-term Palestinian refugees were more likely to suffer from NCD's, poor physical functioning, physical limitations and impaired vision and hearing when compared to shorter-term Syrian refugees [52]. However, a study of Mozambican refugees reported lower poorer nutritional status among those who had been displaced for a shorter period of time [49].

Health-related factors One study in the Democratic Republic of Congo observed that taking no physical exercise, taking multiple prescription drugs, and limited mobility and functioning were associated with malnutrition [24]. The study with Rwandan refugees in Tanzania reported that malnutrition had a negative effect on physical functioning in terms of handgrip strength [46]. The related qualitative study reported perceptions that older people who were physically impaired were at greater risk of poor nutrition due to reduced income [47]. The study of flood survivors in China reported poor sleep patterns, diagnosed chronic disease, and hospitalisation in the preceding year were all associated with poor physical health [56]. The study of refugees in Lebanon noted dementia, poor vision, difficulty walking, poor self-reported health status were associated with lower functional status [52].

\section{Health service access and responsiveness}

Ten studies examined aspects of health service access and responsiveness for older populations (Table 3) $[25,27,31,32,34,39,40,43,52,56]$. The majority of these studies were based on descriptive self-reporting, with no statistical tests.

Five studies reported how older populations had difficulty accessing medical services [27, 31, 34, 40, 52]. Reasons included: a lack of financial resources for treatment and transport; [34, 40,52] the systematic exclusion of older populations from programmes targeting other groups; [31, 34] limited knowledge about appropriate facilities; [52] an absence of outreach programmes; [34] 
and inability to travel to clinics [52]. The study of Syrian and Palestinian refugees in Lebanon reported over 97\% of older populations experienced difficulties accessing medical services and medicines [52].

Four studies assessed health service utilisation [31, 39, 43, 56]. Rural residents in post-earthquake Kashmir were less likely to utilise health services than urban residents, particularly women - with clinician gender playing an important role [31]. A study in eastern Democratic Republic of Congo found a very small proportion (3.3\%) of older populations utilised health services when they were sick [43]. A study of flood-affected residents in Bazhong in China found the two-week healthcareseeking rate was significantly higher than non-flood affected older populations in Sichuan province [56]. The study of surgical outcomes in 21 countries observed a lower proportion of urgent surgical cases when compared to younger age groups $(<50$ years); and the most commonly performed surgical procedures for older people included herniorrhaphies, simple and extensive wound debridement, abscess incision and drainages, minor tumorectomies, and urological procedures [55].

Four studies addressed the responsiveness of health services to the needs of older populations [25, 31, 32, 34]. The qualitative study of Bam earthquake survivors in Iran revealed they perceived services to be inappropriate, with a lack of respect paid to the needs and dignity of older people [25]. Another qualitative study of survivors of the 2004 Tsunami in Sri Lanka observed that older populations felt that they were not adequately consulted about their specific needs [34]. The two remaining studies assessed service responsiveness from the perspective of health service providers after the $2005 \mathrm{Kashmir}$ earthquake in Pakistan, and found that many of their medical problems were undertreated, [31] and the level of awareness of the special needs of older populations was inadequate among all types of healthcare providers [32].

\section{Quality of the evidence}

A commonly recurring issue with the quantitative studies was the limited statistical analysis, including a substantial proportion of the studies only performed descriptive bivariate analysis and so could not control for potential confounding [24, 28, 29, 31, 35-38, 40, 42, $45,48,49,52-56]$. Only four studies reported descriptive prevalence without calculating confidence intervals or statistical significance tests where it would have been appropriate [31, 32, 35, 43]. Many of the studies did not justify their sample size, and non-response rates were rarely reported. Furthermore, the representativeness of some study populations was negatively affected by suboptimal sampling strategies $[24,29,36,46,48,49,52$, 53, 59]. Many of the included studies did not employ comparison groups, making it difficult to interpret whether a particular factor was more likely to influence an outcome in older populations than in the general population. Of the studies that did include a comparison group, the selection process was often poorly justified $[36,52]$. Inadequate justification was also given for the selection of particular outcome measures. Among the qualitative studies, a superficial engagement with the role of the researcher and their subjectivity was a common weakness. The scores for the quality appraisal of individual studies are given in Tables 2 and the detailed results provided in Additional file 3.

\section{Discussion}

This is the first systematic review to examine the evidence related to the specific health needs and vulnerabilities of older populations affected by humanitarian crisis in LMICs. The majority of the 36 studies meeting eligibility criteria were cross-sectional in design, restricting our ability to imply causation between vulnerability factors and health outcomes. In light of the limited breadth and quality of evidence, the following findings should be treated with caution.

This review identified that older age, female gender, socio-economic deprivation and rural residency were frequently associated with adverse health outcomes, reflecting findings from elsewhere for mental health, $[60,61]$ and nutrition [62]. The influence of female gender with worse health outcomes is consistent with existing research in stable settings and highlights the importance of genderdisaggregated data and further research on older women's health needs in humanitarian crises $[61,63,64]$. The discrepancy in health outcomes between urban and rural areas is particularly concerning given that the majority of older populations in low-income countries live in rural areas [65]. Many of these risk-factors, particularly for mental health outcomes, are similar to those in all-age adult populations affected by humanitarian crises [61, 66, 67]. The limited number of studies on non-communicable diseases is also surprising given their higher burden among older people and increasing concern about noncommunicable diseases in humanitarian crises [68].

The limited quantity and quality of research can be partly attributable to the inherent complexity of providing services and conducting research during humanitarian crises, but such research has been successfully undertaken with other population in humanitarian crises [69]. We identified no intervention studies on the effectiveness of existing health interventions specifically with older populations. As the context of humanitarian crises can make randomized control trials difficult to carry out (though by no means impossible [69]), quasiexperimental methods and variants such a stepped-wedge approaches could be used to gain a fuller understanding of the effectiveness (and cost-effectiveness) of health 
programs in meeting the needs of older populations in humanitarian crises. Routine service data could also be more effectively utilised, but this is currently hampered by the common absence of routine age-disaggregated data for older populations [70, 71]. There also needs to be considerably more qualitative research to better understand the perspectives of older populations and health care providers.

In addition to the above research recommendations, humanitarian agencies should consider ways to strengthen their work and capacity to better understand and address the health needs of older people. This includes strengthening and adhering to best practice guidelines for older people in humanitarian crises [9]. UNHCR's Accountability Framework for Age, Gender and Diversity Mainstreaming [72] provides some information on activities for older people but much more detailed and rigorous data reporting is required. This necessitates the collection of age disaggregated routine data (as done by the Office of U.S. Foreign Disaster Assistance (OFDA) which requests disaggregated data for older age groups of 50-59 and then 60+) as well as specific data on the health needs of older people. Other activities include more training and sensitisation for humanitarian health workers on detecting and reporting the health needs of older people. This all requires substantially greater financial investment given the negligible number of funded aid projects specifically for older people in humanitarian crises. For example, of 16,221 humanitarian projects implemented between 2010 and 2014, only 74 projects were funded which included at least one activity specifically targeting older people [7].

This review has highlighted considerable weaknesses in the quantity and quality of research on the health needs of older people in humanitarian crises. While recognising the inherent constraints of humanitarian settings, the lack of research does suggest low levels of awareness and prioritisation of the needs of older populations among the heath care actors and researchers in humanitarian crises.

\section{Limitations}

For the quality review, the NOS does not employ weighted scores for different categories and so studies can receive a strong score while still failing to consider important factors such as the representativeness of the study sample. Bivariate results were extracted where multivariate analysis was not conducted, and so these do not adjust for potential confounders.

\section{Conclusions}

The findings from this review suggest low levels of awareness and appreciation of the needs of older populations among humanitarian heath care actors and researchers. The breadth and depth of evidence should be urgently strengthened in order to better understand the health needs of older populations and the effectiveness and appropriateness of health interventions in meeting these needs.

\section{Additional files}

Additional file 1: Complete search terms. (DOCX $49 \mathrm{~kb}$ )

Additional file 2: PRISMA checklist. (DOCX $17 \mathrm{~kb}$ )

Additional file 3: Detailed Quality Appraisal Results. (DOCX 23 kb)

\section{Acknowledgements}

None.

Funding

No external funding was used for the research for this manuscript.

Availability of data and materials

The complete data extraction sheet used for the study can be obtained from the corresponding author (Bayard Roberts).

\section{Authors' contributions}

EM conceived of the idea. EM and BR finalised the study design and protocol. EM and JS conducted the data searching, screening, and extraction. EM led the writing of the manuscript, with input from BR and JS. All authors read and approved and the final manuscript.

Ethics approval and consent to participate

No ethics approval was required for this study as it was a literature review using studies already in the public domain.

\section{Consent to participate}

Not applicable.

\section{Competing interests}

Bayard Roberts is Editor-in-Chief of Conflict in Health. He was not involved in handling this manuscript.

\section{Publisher's Note}

Springer Nature remains neutral with regard to jurisdictional claims in published maps and institutional affiliations.

Received: 14 June 2017 Accepted: 19 October 2017

Published online: 11 December 2017

\section{References}

1. UN Department of Economic and Social Affairs (UNDESA) Population Division. World population prospects: The 2015 revision. New York: UNDESA; 2015.

2. CRED. People affected by conflict - humanitarian needs in numbers. Brussles: Centre for Research on the Epidemiology of Disasters; 2013.

3. CRED, The human cost of natural disasters 2015: A global perspective. 2015, Centre for Research on the Epidemiology of Disasters: Brussels.

4. United Nations. World Population Prospects: The 2010 revision. Population Division New York: Department of Economic and Social Affairs; 2011.

5. WHO. Global Health and ageing. Geneva: World Health Organization/ National Institute on Ageing; 2011.

6. USAID. Ukraine - Conflict Fact Sheet \#7, Fiscal Year 2015. 2015; Available from: https://www.usaid.gov/sites/default/files/documents/1866/ukraine_fs07_0812-2015.pdf.

7. HelpAge International. HelpAge International: London. End the neglect: a study of humanitarian financing for older people, 2016.

8. Cherniack EP. The impact of natural disasters on the elderly. Am J Disaster Med. 2008:3(3):133-9. 
9. HelpAge International. Older people in disasters and humanitarian crises: Guidelines for best practice. HelpAge International: London. 2015.

10. Hutton D. Older people in emergencies : considerations for action and policy development. Geneva: World Health Organization; 2008.

11. IASC. Humanitarian action and older persons. Geneva: Inter-Agency Standing Committee; 2008.

12. $\mathrm{WHO}$, Older persons in emergencies. An active ageing perspective. Geneva: World Health Organization; 2008.

13. Burton A, Breen C. Older refugees in humanitarian emergencies. Lancet. 2002;360(Suppl):s47-8.

14. Fernandez $L S$, et al. Frail elderly as disaster victims: emergency management strategies. Prehosp Disaster Med. 2002;17(2):67-74.

15. Ngo E, Disasters W, Collide A. Reviewing vulnerability of the elderly. Natural Hazards Review. 2001;2(Special Issue: The second assessment in action - multidisciplinary perspectives on sustianble hazards mititigations):80-9.

16. Virgincar A, Doherty S, Siriwardhana C. The impact of forced migration on the mental health of the elderly: a scoping review. Int Psychogeriatr. 2016:1-8.

17. World Bank. Country and Lending Groups. 2015 [cited 20159 August]; Available from: http://data.worldbank.org/about/country-and-lendinggroups

18. WHO. Humanitarian Health Action Dictionary. 2017; Available from: http://www.who.int/hac/about/definitions/en/index.html.

19. Humanitarian Coalition. What is a Humanitarian Emergency? 2015 [cited 201526 July]; Available from: http://humanitariancoalition.ca/info-portal/ factsheets/what-is-a-humanitarian-emergency.

20. Wells, G., et al., The Newcastle-Ottawa scale (NOS) for assessing the quality of nonrandomised studies in meta-analyses. 2000. http://www.ohri.ca/ programs/clinical_epidemiology/oxford.asp. Accessed 27 Oct 2017.

21. Herzog R, et al. Are healthcare workers' intentions to vaccinate related to their knowledge, beliefs and attitudes? A systematic review. BMC Public Health. 2013;13(1):154.

22. Critical Appraisal Skills Programme (CASP). Qualitative Research Checklist. 2013 [cited 20153 July]; Available from: http://media.wix.com/ugd/dded87 29c5b002d99342f788c6ac670e49f274.pdf.

23. Moher D, et al. Preferred reporting items for systematic reviews and metaanalyses: the PRISMA statement. J Clin Epidemiol. 2009:62(10):1006-12.

24. Andre MB, et al. Mini nutritional assessment and functional capacity in community-dwelling elderly in rural Luozi, Democratic Republic of Congo. Geriatr Gerontol Int. 2013;13(1):35-42.

25. Ardalan A, et al. Older people's needs following major disasters: a qualitative study of Iranian elders' experiences of the bam earthquake. Ageing \& Society. 2010;30(1):11-23.

26. Ardalan A, et al. Post-disaster quality of life among older survivors five years after the bam earthquake: implications for recovery policy. Ageing Soc. 2011;31(2):179-96

27. Ardalan A, et al. Impact of the 26 December 2003 bam earthquake on activities of daily living and instrumental activities of daily living of older people. Prehospital \& Disaster Medicine. 2011;26(2):99-108.

28. Arlappa $\mathrm{N}$, et al. Prevalence of chronic energy deficiency in rural-dwelling older Indian adults during a period of severe drought. J Nutr Elder. 2009;28(3):301-12.

29. Cao $X$, et al. The prevalence and risk factors for psychological distress in older men and women affected by the Wenchuan, China earthquake. Australasian Journal on Ageing. 2014;33(3):E20-6.

30. Chaaya $\mathrm{M}$, et al. Religiosity and depression in older people: evidence from underprivileged refugee and non-refugee communities in Lebanon. Aging Ment Health. 2007;11(1):37-44.

31. Chan EY, Griffiths S. Comparision of health needs of older people between affected rural and urban areas after the 2005 Kashmir. Pakistan earthquake Prehospital \& Disaster Medicine. 2009:24(5):365-71.

32. Chan EY. Why are older peoples' health needs forgotten post-natural disaster relief in developing countries? A healthcare provider survey of 2005 Kashmir, Pakistan earthquake. Am J Disaster Med. 2009;4(2):107-12.

33. Chen $\mathrm{G}$, Shen $\mathrm{H}$, Chen $\mathrm{G}$. A cross-sectional study on posttraumatic stress disorder among elderly Qiang citizens 3 years after the Wenchuan earthquake in China. The Canadian Journal of Psychiatry/La Revue canadienne de psychiatrie. 2012;57(9):547-53.

34. Duggan $\mathrm{S}$, et al. Perceptions of older people on disaster response and preparedness. Int J Older People Nursing. 2010;5(1):71-6.
35. Godfrey N, Kalache A. Health needs of older adults displaced to Sudan by war and famine: questioning current targeting practices in health relief. Soc Sci Med. 1989;28(7):707-13.

36. Goenjian AK, et al. Posttraumatic stress disorder in elderly and younger adults after the 1988 earthquake in Armenia. Am J Psychiatry. 1994;151(6):895-901.

37. Handicap International/HelpAge International, Hidden victims of the Syrian crisis: disabled, injured and older refugees. 2014.

38. Havelka M, Lucanin JD, Lucanin D. Psychological reactions to war stressors among elderly displaced persons in Croatia. Croatian Medical Journal. 1995;36(4):262-5.

39. Jia Z, et al. Are the elderly more vulnerable to psychological impact of natural disaster? A population-based survey of adult survivors of the 2008 Sichuan earthquake. BMC Public Health. 2010;10:172.

40. Johns Hopkins Bloomberg School of Public Health and The Institute for Policy Studies, Aging in Displacement: Assessing Health Status of Displaced Older Adults in the Republic of Georgia. 2012, Johns Hopkins Bloomberg School of Public Health.

41. Kohn R, et al. Prevalence, risk factors and aging vulnerability for psychopathology following a natural disaster in a developing country. International Journal of Geriatric Psychiatry. 2005:20(9):835-41.

42. Li Y, et al. Sense of community and depressive symptoms among older earthquake survivors following the 2008 earthquake in Chengdu China. Journal of Community Psychology. 2011;39(7):776-85.

43. Lutala MP, et al. Health care seeking and financial behaviours of the elderly during wartime in Goma, Democratic Republic of Congo. African journal of primary health care and Fam Med. 2010;2(1)

44. Nomura A, et al. Post-traumatic stress disorder among senior victims of tsunami-affected areas in southern Sri Lanka. Acta Medica Nagasakiensia. 2010;55(1):41-6.

45. Pieterse S, Manandhar M, Ismail S. The nutritional status of older Rwandan refugees. Public Health Nutr. 1998;1(4):259-64.

46. Pieterse $S$, Manandhar $M$, Ismail S. The association between nutritional status and handgrip strength in older Rwandan refugees. Eur J Clin Nutr. 2002;56(10):933-9.

47. Pieterse S, Ismail S. Nutritional risk factors for older refugees. Disasters. 2003;27(1):16-36.

48. Prueksaritanond S, Kongsakol R. Biopsychosocial impacts on the elderly from a tsunami-affected community in southern Thailand. J Med Assoc Thail. 2007:90(8):1501-5.

49. Ramji S, Thoner G. Nutritional status of displaced Mozambican elderly living in Mozambique and Zimbabwe. Surveyed in June-July 1987. Naringsforskning. 1991;35(1):24-31.

50. Sibai AM, Fletcher A, Armenian HK. Variations in the impact of long-term wartime stressors on mortality among the middle-aged and older population in Beirut, Lebanon, 1983-1993. Am J Epidemiol. 2001;154(2):128-37.

51. Sibai AM, Yount KM, Fletcher A. Marital status, intergenerational coresidence and cardiovascular and all-cause mortality among middle-aged and older men and women during wartime in Beirut: gains and liabilities. Soc Sci Med. 2007;64(1):64-76.

52. Strong J, et al. Health status and health needs of older refugees from Syria in Lebanon. Confl Heal. 2015;9(12)

53. Viswanath $B$, et al. Psychological impact of the tsunami on elderly survivors. Am J Geriatr Psychiatry. 2012;20(5):402-7.

54. Wen J, et al. A retrospective study of geriatric trauma at a large teaching hospital after the 2008 Wenchuan earthquake. International Journal of Gerontology. 2010;4(3):115-9.

55. Wong EG, et al. Operative procedures in the elderly in low-resource settings: a review of Medecins sans Frontieres facilities. World J Surg. 2015;39(3):652-7.

56. Wu J, et al. A cross-sectional survey on the health status and the healthrelated quality of life of the elderly after flood disaster in Bazhong city, Sichuan, China. BMC Public Health. 2015;15:163.

57. Zhang $L$, et al. The clinical features and outcome of crush patients with acute kidney injury after the Wenchuan earthquake: differences between elderly and younger adults. Injury. 2012;43(9):1470-5.

58. Zhang Z, et al. Post-traumatic stress disorder, anxiety and depression among the elderly: a survey of the hard-hit areas a year after the Wenchuan earthquake. Stress and Health: Journal of the International Society for the Investigation of Stress. 2012;28(1):61-8. 
59. Zhang Z, et al. A pilot investigation on the status of quality of life of the rural old men after the earthquake in Wenchuan. Xiandai Yufang Yixue [Modern Preventive Medicine]. 2012;4:880-881-90.

60. Brewin CR, Andrews B, Valentine JD. Meta-analysis of risk factors for posttraumatic stress disorder in trauma-exposed adults. Journal of Consulting \& Clinical Psychology. 2000;68(5):748-66.

61. Roberts B, Browne J. A systematic review of factors influencing the psychological health of conflict-affected populations in low- and middleincome countries. Global public health. 2011;6(8):814-29.

62. Pirlich M, Lochs H. Nutrition in the elderly. Best Pract Res Clin Gastroenterol. 2001;15(6):869-84.

63. Castel H, Shahar D, Harman-Boehm I. Gender differences in factors associated with nutritional status of older medical patients. J Am Coll Nutr. 2006;25(2):128-34.

64. Seedat S, et al. CRoss-national associations between gender and mental disorders in the world health organization world mental health surveys. Arch Gen Psychiatry. 2009;66(7):785-95.

65. Kinsella K, Wan H. An Aging World: 2008, in International Population Reports. DC: U.S. Census Bureau: Washington; 2009.

66. Miller KE, Rasmussen A. War exposure, daily stressors, and mental health in conflict and post-conflict settings: bridging the divide between traumafocused and psychosocial frameworks. Soc Sci Med. 2010;70(1):7-16.

67. Porter M, Haslam N. Predisplacement and postdisplacement factors associated with mental health of refugees and internally displaced persons: a meta-analysis. JAMA. 2005;294(5):602-12.

68. Jobanputra K, et al. Three steps to improve Management of Noncommunicable Diseases in humanitarian crises. PLoS Med. 2016;13(11):e1002180.

69. Blanchet $\mathrm{K}$, et al. Evidence on public health interventions in humanitarian crises. Lancet. 2017;

70. du Cros, P., S. Venis, and U. Karunakara, Should mortality data for the elderly be collected routinely in emergencies? The practical challenges of agedisaggregated surveillance systems. Trans R Soc Trop Med Hyg, 2013. 107(11): p. 669-671.

71. Mazurana DBP, Gupta H, Walker P. Sex and age matter: improving humanitarian response in emergencies. Feinstein International Center. 2011;

72. UNHCR. UNHCR Age, Gender and Diversity Accountability Report 2015. Geneva: UNHCR; 2016.

\section{Submit your next manuscript to BioMed Central and we will help you at every step:}

- We accept pre-submission inquiries

- Our selector tool helps you to find the most relevant journal

- We provide round the clock customer support

- Convenient online submission

- Thorough peer review

- Inclusion in PubMed and all major indexing services

- Maximum visibility for your research

Submit your manuscript at www.biomedcentral.com/submit 